\title{
The Problems and Countermeasures of Market Town Construction in Longyang District of Baoshan
}

\author{
Yanfang Zhou ${ }^{1 a^{*}}$ and Linghong Meng ${ }^{2 b}$ \\ ('Baoshan university,No.16, expeditionary road, Longyang district, Baoshan city, Yunnan ,China \\ ${ }^{2}$ Baotou normal university,No.2, science road, Qingshan district, Baotou city, Inner Mongolia, China) \\ aqueti100@126.com, ${ }^{b}$ desmong02@163.com
}

Keywords: Longyang district; Market town; Problems; Suggestions

\begin{abstract}
Longyang district is the seat of Baoshan municipal government, with a land area of 4855.51 square kilometers. Its natural geographical environment and climatic conditions are complex and diverse. This paper takes the rural market town of Longyang district as research object, from the policy analysis all levels of government requirement of the construction of rural market town, through field survey and the interview to understand each actual situation of the rural town construction, sums up management problems that exist in the rural town construction, again based on to put forward suggestions. We hope that it provide reference for decision-making at all levels of government related department.
\end{abstract}

\section{Introduction}

Although the study of market towns has been carried out for more than 30 years, the connotation and extension of market towns are still unclear to both the academic community and the public. From the perspective of national laws and regulations, only standards for the division of urban and rural areas and administrative regulation of village and town planning and construction have clear regulations on market towns, other relevant laws and regulations do not mention this concept. A market town is a non-construction town where The governments of townships or nationality townships is located and which has been confirmed by the people's government at the county level as a service center of economy, culture and life in a certain rural area. [1] It is stipulated in the regulations on the planning and construction of villages and market towns. From the definition, market towns can be included in the scope of small towns. This concept is widely used in urban and rural planning and new rural construction.

Market Town as between rural and urban settlement type which function is to supply the village for production and living materials, buy from agricultural products, and meet the residents in their jurisdiction for public services such as education, medical, entertainment and others.[2] It is a link between urban and rural, and likely to grow into organizational system town in certain condition.

\section{Overview of Longyang District, Baoshan City}

Longyang district is located in the Baoshan city east, between the Nu River and Lancang River, the southern section of the Hengduan Mountains. It is $486 \mathrm{~km}$ from kunming, the provincial capital, and $279 \mathrm{~km}$ from the China-Myanmar border in the west. Mountains ups and downs may stick in land area 4855.51 square kilometers, the highest elevation 3655.9 meters, the lowest elevation 648 meters. There are many rivers in Longyang district, including the $\mathrm{Nu}$ River and Lancang River. Because of the large altitude difference within the territory, water resources are relatively rich.

Longyang district belongs to subtropical monsoon climate. In addition, because of low latitude and high altitude and complex terrain elevation differences, it forms a vertical three-dimensional climate, vulgar "one mountainat four seasons, different weather within $10 \mathrm{~km}$ ". In most areas of the region, there is no cold winter, no hot summer, average annual temperature of 15.5, annual frost-free period over 290 days, annual average rainfall of $966.5 \mathrm{~mm}$, mainly in the summer and autumn seasons. 
The complex and diverse geographical and climatic conditions make Baoshan rich in geothermal resources, animal and plant resources, and also create good natural conditions for the development of various agricultural economies.

By 2014, Longyang district had jurisdiction over 2 streets, 6 towns, 6 townships and 4 nationality townships. The streets, towns, townships and nationality townships under the jurisdiction of Longyang district are shown in table 1. Although these 16 administrative districts have different names, they belong to the same administrative divisions at the same level. The administration center of these 16 regions are the central market towns in Longyang district and the object of this paper.

Table 1 the streets, towns, townships and nationality townships under the jurisdiction of Longyang district

\begin{tabular}{ll}
\hline political division & \multicolumn{1}{c}{ name } \\
\hline Streets(2) & Yongchang street, Xinghua street \\
\hline Towns(6) & $\begin{array}{l}\text { Banqiao town, Hetu town, Hanzhuang town, Pupiao town, Wayao town, } \\
\text { Lujiang town }\end{array}$ \\
\hline Townships(6) & $\begin{array}{l}\text { Jinji township, Xinjie township, Xiyi township, Bingma township, } \\
\text { Wadu township,Shuizhai township }\end{array}$ \\
\hline $\begin{array}{l}\text { nationality } \\
\text { townships(4) }\end{array}$ & $\begin{array}{l}\text { Yangliu bai yi nationality township, Wama yi bai nationality township, } \\
\text { township yi miao nationality township, Mengkuan yi dai nationality }\end{array}$ \\
\hline
\end{tabular}

\section{Current Situation and Problems of Market Town Construction in Longyang District, Baoshan City}

In the system of urban development in Yunnan province during the "12th Five-year Plan" period, Market town is the third level in the multi-level structure system which are made up of regional central cities, government resident cities, market town,village. It's the link between the city and the village.

As for how to build a market town, Yunnan province has put forward the idea of building a characteristic town. In combination with its own characteristics, each city further puts forward the guiding opinions on the construction of a characteristic town in the area under its jurisdiction. Since 2011, Baoshan city has seized the development opportunity of urbanization construction in Yunnan province, and carried out small-town construction in a planned and step-by-step manner in combination with Baoshan city. As the center of Baoshan city, Longyang district's construction of market towns is not only an important part of the construction of market towns, but also a pioneer in leading the demonstration. Based on the analysis of institutional text and field research, this paper sorted out the current situation and existing problems of market town construction in Longyang district, mainly including the following aspects:

From the perspective of system construction:the policy documents guiding the construction of market towns are basically complete. In 2012, people's government of Baoshan city issued the opinions on accelerating the construction of characteristic towns. This document clarifies the general idea of market town construction in Baoshan city. Based on the scientific outlook on development, it puts forward the strategy of carrying out characteristic driving, and carries out the construction of market towns in different stages according to local conditions. In the concrete implementation steps, it is proposed to plan first, improve and optimize functions of market towns through planning.[3] In the same year, the government of Baoshan city also issued the opinions on strengthening the compilation and implementation of town and township planning to guided the planning of the market towns. This document required to complete the planning of 10 provincial-level characteristic towns and 27 city-level characteristic towns in 2012, complete the compilation of detailed planning, control rules and the recent construction plans for all towns in the 
city in 2013.[4]

The two documents are the guiding documents for the construction of Baoshan market town.They clearly stipulate the general idea, target task, main content, current work focus, implementation steps,safeguard measures of the construction, so they are operable.[5]

From the perspective of construction targets: the targets set during the "12th five-year plan" period have not been fully achieved. By the end of the "12th five-year plan", the planning of 10 provincial-level characteristic towns and 27 city-level characteristic towns had been completed. Among them, the planning and review of 3 provincial-level characteristic towns and 7 city-level characteristic towns in Longyang district have been completed, and implementation has become the focus of the next step. But in research we found that in addition to provincial-level and city-level characteristic towns, the planning of most market towns in Longyang district is still in progress. Shortage of funds is the main cause of the planning is slow work.

From the perspective of infrastructure: the infrastructure construction of market towns is not perfect. The main problems existing in the construction of infrastructure of market towns are as follows: First, lack of sewage collection and treatment facilities. Only a few market towns have sewage collection pipelines, and all have no sewage treatment facilities. Central market towns regularly collect and burn garbage, but these facilities are backward in function. Second, the road connecting nearby towns is of low grade and bad condition. Roads are mostly 2-4 levels of road, most mountainous areas and poor rural roads are 4.5 meters wide 4 levels of road. Narrow roads, simple aging facilities, geological disasters are common. Third, all market towns have access to electricity and water, but these facilities are backward in function. Taking drinking water as an example, the drinking water in Yangliu town was brought directly from the Xiaohaiba reservoir to the town without being purified or sterilized because there was no relevant equipment.

Among all kinds of infrastructure, roads restrict the economic and social development of market towns most obviously. At present, the transportation cost is high and time-consuming, which seriously restricts the construction and development of market towns in Longyang district.

From the perspective of public service facilities: the public service facilities of central market towns are basically complete. Public service facilities in central market towns are basically complete, especially administrative, education, cultural and medical facilities are more perfect than other public service facilities. They can provide basic education, medical treatment, agricultural and sideline products trading, shopping and other services for people in the township area. In recent years, with the rapid development of e-commerce and the popularization of shopping on the Internet, central market towns have rural taobao stores and more than two express companies. Some farmers and cooperatives also use the Internet to sell agricultural products.

From the perspective of industrial structure: the structure is unreasonable and lacks competitive characteristic industries. The economic development of Longyang district is characterized by the unreasonable structure and the low technological content in industries. In general, the industrial structure of Longyang district is similar to that of the other 3 counties and 1 city in Baoshan city. Agriculture and agricultural product processing industry are the main source of revenue, such as tobacco, sugar, wine, etc. The proportion of secondary industry accounts for regional financial revenue is very small. Except Hanzhuang town, the pillar industry of each town in Longyang district is still predominantly agricultural planting and primary processing, initially formed some special industries, such as tobacco, coffee, walnuts, silkworm cultivation and processing. In addition to aromatic tobacco, other agricultural products have not formed their own characteristics and core competitiveness compared with similar products.[6,7]

From the perspective of construction management organizations and personnel of market towns: all towns have relevant institutions and personnel, but the management level needs to be improved. All towns are attaches great importance to the construction of market town, have the corresponding functional departments - Land and Town Planning and Construction Service Center .There are two more staff in charge of town planning, construction and daily management work. 
Through the survey we found that most towns leadership are more attention in the construction of town, Some towns leaders and workers are aware of the relevant policies issued by governments at all levels, but their understanding is not deep and accurate enough, leading to problems such as inaccurate and clear positioning of market towns and slow progress of construction work. To be sure, after the plan is passed, all towns can strictly follow the plan and relevant policies.

From the perspective of construction funds: single investment, lack of funds. There are two main sources of funds for the construction of infrastructure and public service facilities in market towns: First, various types of state special funds; Second, land auctions. In practice, the capital for the construction of market towns mainly depends on the government's investment, that is the special funds for medical treatment, education and cultural facilities construction allocated by governments at all levels. The situation of selling land to developers is relatively small in the surveyed market towns, because the land investment cost is high, the recycling cycle is long, the income is low, and the developers are often reluctant to invest. Government special funds can only be used to construction of specific facilities, many projects is not in the scope of special funds to support, especially related to the living environment of sewage garbage disposal facilities, farmers market, etc.

\section{The Strategies and Suggestions about Market Town Construction and Management in Longyang District of Baoshan City}

Town is the end of the city to the village, is the first stop of the rural areas to cities to the world.If the market town cannot play the role of the connection, the development of urban and rural areas will be constrained. There are the strategies and suggestions about the construction and management of town in Longyang district of Baoshan city.

Strengthen the mechanism about the policy convey, execution and supervision. It is a process of developing and perfecting constantly that all governments' the concept of the construction in market town. Therefore, the lower level government should keep pace with the higher level government and timely update the ideas and objectives of market town construction.In 2007, the people's government of Yunnan province released the suggestions about speed up the development of characteristic town. Added the concept of first-class characteristic town based on the concept of construction of characteristic town in this file.First-class characteristic town is the updated. It is the core zone of system town, which covers 1-3 square kilometers, has more concentrated and perfect functions which includes production, urbanization, humanities and culture.[8,9]

Longyang district which has 3 provincial-level and 7 city-level characteristic towns should seize the opportunity, make the target, train of thought and the measures, choose 1-2 towns declare national-level or provincial-level characteristic towns. It can improve the level of the town, secure funding and policy support, and provide construction and development experience for other towns in Baoshan city.

In addition, the town governments should perfect the policies and regulations, guidance, supervision and rewards and punishment mechanism. In terms of security, it is necessary to clarify the proportion of funds that governments at all levels spend on planning and formulation, and increase the financial support from higher authorities. Secondly, the departments of city and district strengthen the guidance of market town planning and review. The planning of towns localization also towns and cities, should plan as a whole. The development orientation of each town should be determined on the basis of regional development orientation to ensure the integration of urban and rural development. Thirdly, the higher government departments should formulate operational supervision and inspection measures, strengthen the supervision and inspection of the implementation of policies, and put all work into practice. The higher government departments should give policy support and financial rewards to those towns that have done well, and hold their leaders accountable to those towns that have not done well.

Increase financial support for market town construction. On the whole, the fiscal revenue is lower in all towns of Longyang district, most of the towns' fiscal revenue is about 10 million Yuan 
per year, and towns' disposable part is less. The towns' funds used in the construction market town are little. The capital required for the construction of market towns is huge. For example, the funds in preparation of planning requires 0.4-1.2 million Yuan per item. Every planning of provincial-level and municipal-level characteristic town has 50-100 thousands Yuan subsidies. Other towns of the cost of planning require the support of county or district. The planning progresses rapidly in the large support towns, while slow progress conversely even to stop. Therefore, the funds of the town construction especially in the planning stage still need government investment funds.

Optimize and upgrade the town infrastructure and public service functions. Longyang district infrastructure is imperfect, public service facilities almost complete. In view of this situation, priority should be given to infrastructure improvement and functional improvement in planning and construction. Public service facilities should be optimized by improving the level of sharing and comprehensive utilization.

To improve infrastructure, we must first upgrade the level of road traffic facilities. From the perspective of the need of industrial development, there are 2 grade highways between towns at least, can basically meet the needs of town economy development. The development of towns needs to improve traffic facilities. The construction of road in city or district should plan as a whole to ensure the scientific, rationality of the road network structure. Secondly, the construction of sewage and garbage disposal facilities should perfect. Sewage treatment facilities are one of the weakest in market town. We should learn advanced practices from other provinces and improve ourselves.

To optimize the function of public service facilities, it is necessary to coordinate the layout of relevant facilities, improve utilization rate through sharing, and avoid low-level and repeated construction. One town jurisdiction tend to form more regular rural market due to geographical and historical factors. Some rural markets may become market towns and share some functions of the central market town, such as the economic service function. In general, a function is generally not be composed of more than two towns, otherwise which is unfavorable for the sharing and use of related services. Planning of town should not build the center of the education or medical facilities in tow places, for example the primary school and middle school or hospitals and nursing homes. This will reduce facilities utilization and waste of money. Similar or related to the public service facilities arranged in the same area, not only save the land resources, also can increase the efficiency of various venues. Mangkuan Ethnic Culture Park is a comprehensive culture square which many functions in a body, such as sports, cultural and artistic performance, the spread of science and technology, entertainment, and so on.

Determine the key points and levels of infrastructure construction around industrial positioning. Accurate and clear positioning is the foundation of scientific planning for the construction of market town. In practice, most towns are always not clear in the positioning. Industry positioning of town is the core content. We should departure from the towns pillar industry, combine with the characteristics of local natural humanities and clear town development orientation. On the basis of clear town positioning, according to different of industries scale and level, the construction of infrastructure and public service facilities should emphasis on different fields. It can strengthen the public service ability of the market town. For example, the market town with production and processing of agricultural and sideline products, should construct a special area for the construction of public service facilities a cold chain logistics park for the acquisition, processing, storage and distribution of farm and sideline products. The planning of town construction should achieve its long-acting and practical, avoid "the different towns have the same looks".

Strengthen the policy knowledge training of market town management personnel. Regular or irregular lectures, visits and other methods are adopted to train leaders and staff in charge of the construction of towns and villages. For example, make the construction planning staff in management department of the provinces, cities and urban and rural introduce about relevant policy. Hire professional teaching knowledge of urban and rural construction planning, We can also visit and learn better about the construction of market towns within and outside the province. Through these measures, leaders and staff of each market town can broaden their horizons, accurately grasp 
various policies and increase their knowledge of market town construction.

Actively guide the public to participate in the construction work. In the survey, we found that the residents of market towns paid less attention to the construction of market towns and did not know much about the development of market towns, let alone actively participated and made suggestions. The participation of residents is an indispensable force in the planning and construction of market towns. The government should actively guide public participation in various forms. First, the government can organize a planning publicity meeting and invite people in the planning area to participate in the event to introduce the contents of the planning and the benefits brought by the completion of the project. Second, the media can timely report to the public about the progress of the implementation of the plan, the difficulties encountered and the solutions to attract the public's attention. Third, through the exhibition hall (room) to publicize the planning and construction of the market towns, and invite people to visit. Finally, a long-term mechanism for soliciting opinions and Suggestions from the public will be established in the formulation and implementation of the plan, and reasonable Suggestions are implemented in the work.[10]

The technology town will be listed as one of the characteristic towns. During the " 12 th five-year plan" period, Baoshan city has identified 7 types of characteristic towns, including agricultural, industrial, tourist, commercial and so on. We think technology town should also be added. In today's society, the development of all industries requires more and more scientific and technological innovation.

Therefore, it is very important to carry out technological breakthrough and research activities in combination with the problems in local economic and social development. As the political and cultural center of Baoshan city, Longyang district should actively introduce a number of scientific research institutions related to local economic and social development into Baoshan. Choose a small town with convenient transportation and convenient environment (such as Jinji town) to build a technology town, with technology, patents, new products and new technology of r\&d and trading as its characteristic industries. This is not only a model for constructing green and environment-friendly market town, but more importantly, it can provide continuous intellectual support for the development of Baoshan local economy.

\section{Acknowledgements}

This paper is the research results of Baoshan Philosophy and Social Support Project(YB20160183).

\section{References}

[1] <Administrative Regulation of Village and Town Planning and Construction>, http://www.mohurd.gov.cn/fgjs/xzfg/200611/t20061101_158933.html,2017-5-14.

[2] S.C.Fan: economic manager,(2015)No.4,p100-102. (In Chinese)

[3] Opinions on accelerating the construction of characteristic towns and villages, RD(2012).

[4] Opinions of baoshan municipal people's government on strengthening the compilation and implementation of town and township planning,public document(2012).

[5] W.F.Qi:Planning Studies, Vol.35(2011)No.9,p19-25. (In Chinese)

[6] T.T.Cheng,L.S.Zhang: Architectural Journal,(1986)No.12,p33-37. (In Chinese)

[7] C.X.Cui,Z.C.Zhang and X.J.Yang:Journal of northwest university (philosophy and social science edition), Vol.41(2011)No.4,p69-73. (In Chinese)

[8] Interpretation of <Opinions of Yunnan Provincial People's Government on Accelerating the Development of Special Towns>, http://www.yr.gov.cn/view,2017-5-26.

[9] Report from the Press Conference on $<$ Yunnan Provincial People's Government on Accelerating the Development of Special Towns>, http://www.gjxwlm.com, 2017-4-11.

[10] G.S.Zhu,Z.S.Dong: Seminar on construction and management of small towns with yunnan characteristics(Baoshan,2015),(2015),p1-8. 